\title{
Co-Pt Clusters on a Highly Oriented Fe-Co Soft Underlayer in a Co-Pt-TiO 2 Perpendicular Medium
}

\author{
K. Shintaku \\ Akita Research Institute of Advanced Technology (AIT), 4-21 Sanuki, Araya, Akita 010-1623, Japan
}

\begin{abstract}
A granular-type medium with a highly oriented high- $\mathrm{B}_{\mathrm{s}} \mathrm{Fe}$-Co soft underlayer (SUL) and a thin $\mathrm{Ru}$ intermediate layer of $4 \mathrm{~nm}$ was prepared. It displayed low $\mathrm{H}_{\mathrm{ch}}\left(\mathrm{H}_{\mathrm{c}}\right.$ in the hard axis direction) value of 1.1 Oe in the SUL and high $\mathrm{H}_{\mathrm{c}}$ of $6.0 \mathrm{kOe}$ in a $\mathrm{Co}-\mathrm{Pt}-\mathrm{TiO}_{2}$ recording layer. The recording layer in the medium has a novel granular structure, namely, well-isolated clusters composed of 5-15 pieces of small Co-Pt grains 4-7 nm in diameter segregated by $\mathrm{TiO}_{2}$. The clusters were oval, with an average area of $213 \mathrm{~nm}^{2}$. At present, the shape and arrangement of the clusters cannot be controlled successfully.
\end{abstract}

Key words: perpendicular recording media, granular film, cluster, Fe-Co soft underlayer, Ru intermediate layer, Ta underlayer.

\section{Introduction}

Perpendicular magnetic recording was proposed about 30 years ago1), and perpendicular recording hard disk drives were first produced commercially last year. Co-Pt based granular film has been used as a recording layer in perpendicular recording media. For highdensity perpendicular recording, media require low noise (high $\mathrm{S} / \mathrm{N}$ ), a moderate saturation field, and high thermal stability. However, it is thought to be very difficult to satisfy the desired conditions for future high recording density by reducing the grain size of a granular film. Consequently, composite media or patterned media are being investigated as an alternative solution.

Reduction of the film thickness of the intermediate layer between the recording layer and the SUL is important for saturation recording. A high- $B_{s}$ SUL is also needed to reduce the film thickness from the viewpoint of industrial production. To solve these problems simultaneously, I prepared an Fe-Co soft underlayer with a high- $\mathrm{B}_{\mathrm{s}}$ of $2.45 \mathrm{~T}$ and $\mathrm{a}$ high crystal orientation and found a novel granular structure in the recording layer.

\section{Experiment}

Samples were prepared in an UHV sputtering system by dc and rf magnetron methods in an Ar gas atmosphere. The composition of the alloy targets was $\left(\mathrm{Co}_{80} \mathrm{Pt}_{20}\right)-\left(\mathrm{TiO}_{2}\right)\left(\mathrm{CoPt}: \mathrm{TiO}_{2}=70: 30\right.$ vol\%, CoPt-TiO 2$)$, $\mathrm{Ru}, \mathrm{Fe}_{70} \mathrm{Co}_{30}(\mathrm{FeCo}), \mathrm{Ir}_{20} \mathrm{Mn}_{80}$ (IrMn), Pt, Ta, and $\mathrm{C}$. The substrates were $\phi 2.5$-inch glass disks. A magnetic field of about 100 Oe in the radial direction of the disk was applied to induce an in-plane magnetic anisotropy during deposition. The base pressure was around $1-3 \mathrm{x}$ $10^{-7} \mathrm{~Pa}$. The substrate temperature was $22^{\circ} \mathrm{C}$.

The film structure was investigated by X-ray diffraction (XRD) using the $\theta-2 \theta$ scan method with $\mathrm{Cu}-\mathrm{K} \alpha$ radiation. Magnetic properties were measured by means of a vibrating sample magnetometer (VSM) calibrated by using standard samples (pure $\mathrm{Ni}$ and $\mathrm{Fe}$ ) and a polar Kerr effect magnetometer. The microstructure was observed by using a transmission electron microscope (TEM).

\section{Results and Discussion}

Figure 1 shows a schematic illustration of a prepared medium. The designed film structure was $\mathrm{C}$ $(6 \mathrm{~nm}) / \mathrm{CoPt}-\mathrm{TiO}_{2} \quad(15 \mathrm{~nm}) / \mathrm{Ru} \quad(4 \mathrm{~nm}) / \mathrm{FeCo} \quad(50$ $\mathrm{nm}) / \mathrm{IrMn} \quad(10 \quad \mathrm{~nm}) / \mathrm{Pt} \quad(10 \quad \mathrm{~nm}) / \mathrm{Ta} \quad(5 \mathrm{~nm}) /$ glass substrate. The $\mathrm{B}_{\mathrm{s}}$ of an FeCo SUL was $2.45 \mathrm{~T}$. IrMn was used as an fcc underlayer to obtain soft magnetic properties in the $\mathrm{FeCo}$ film $^{2)-4)}$, and an antiferromagnetic layer to pin the $\mathrm{FeCo}_{\text {film }}$ ). A Pt underlayer is effective in increasing the crystal orientation of the IrMn, which is necessary in order to enhance the exchange coupling energy between the $\mathrm{FeCo}$ and the IrMn films. It is reported that a CoPt$\mathrm{TiO}_{2}$ recording layer on a $\mathrm{Ru} / \mathrm{Pt}$ film has a wellisolated fine granular structure6).

The crystal orientation of the medium was greatly enhanced by using a thin Ta underlayer. As shown in Fig. 2, a medium with such a Ta underlayer has a very

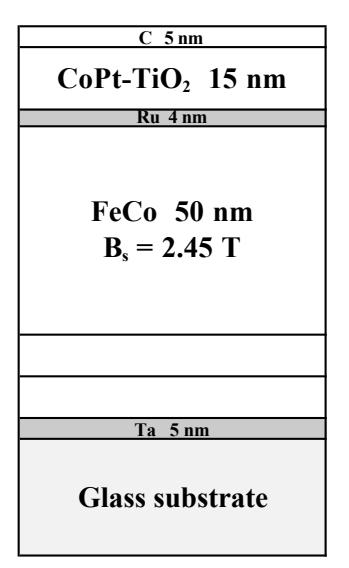

Fig. 1 Schematic illustration of a medium. 


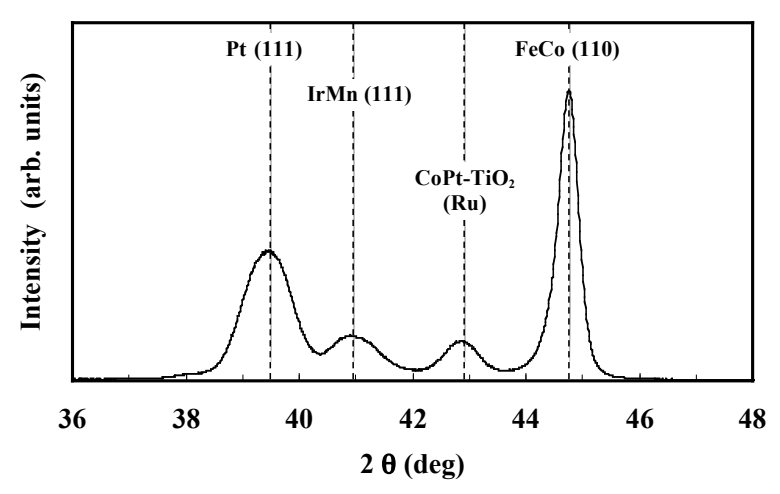

Fig. 2 XRD pattern of the medium.

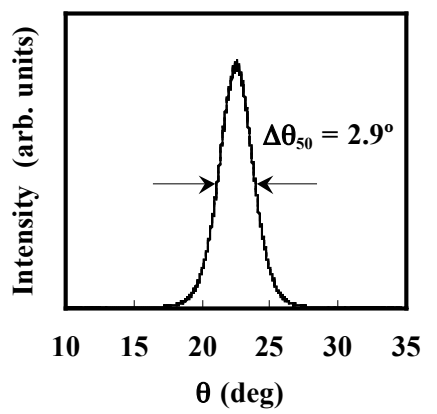

Fig. 3 Rocking curve of the FeCo (110) peak.

large peak intensity in the XRD pattern. The $\Delta \theta_{50}$ value of the FeCo bcc (110) peak was $2.9^{\circ}$, as shown in Fig. 3, while that of the $\mathrm{CoPt}-\mathrm{TiO}_{2}$ hcp (002) peak was $4.5^{\circ}$. The orientation of the $\mathrm{CoPt}-\mathrm{TiO}_{2}$ layer was lower than that of the FeCo layer.

Figure 4 shows the M-H curve of this medium. As the in-plane signal from the recording layer was negligibly small from the measurement of a $\mathrm{CoPt}-\mathrm{TiO}_{2}$ perpendicular single-layered media, this indicates a clear in-plane magnetic anisotropy and good soft magnetic properties of the FeCo SUL. The values of $\mathrm{H}_{\mathrm{ch}}, \mathrm{H}_{\mathrm{c}}$ in the easy axis direction $\left(\mathrm{H}_{\mathrm{ce}}\right)$, the anisotropy field $\left(\mathrm{H}_{\mathrm{k}}\right)$, and the exchange coupling field $\left(\mathrm{H}_{\mathrm{ex}}\right)$ were 1.1 Oe, $28.0 \mathrm{Oe}, 48.7 \mathrm{Oe}$, and $24.8 \mathrm{Oe}$, respectively. The exchange energy $\left(\mathrm{J}_{\mathrm{ex}}\right)$ was estimated to be 0.24 $\mathrm{erg} / \mathrm{cm}^{2}$ from the formula $\mathrm{J}_{\mathrm{ex}}=\mathrm{M}_{\mathrm{s}} \mathrm{H}_{\mathrm{ex}} \mathrm{t}_{\mathrm{FeCo}}$, where $\mathrm{M}_{\mathrm{s}}$ is the saturation magnetization and $t_{\mathrm{FeCo}}$ is the film thickness of the FeCo.

As shown in Fig. 5, the magnetic properties of the CoPt- $-\mathrm{TiO}_{2}$ recording layer were estimated by a Kerr loop. The values of the squareness ratio ( $\mathrm{SQ}), \mathrm{H}_{\mathrm{c}}$, the nucleation field $\left(\mathrm{H}_{\mathrm{n}}\right)$, and the saturation field $\left(\mathrm{H}_{\mathrm{s}}\right)$, were $0.92,6.0 \mathrm{kOe},-0.51 \mathrm{kOe}$, and $14.0 \mathrm{kOe}$, respectively. Large $\mathrm{H}_{\mathrm{c}}$ and squareness ratio were obtained for a medium with a $\mathrm{Ru}$ intermediate layer thickness of $4 \mathrm{~nm}$.

Figure 6 shows an in-plane TEM image of the $\mathrm{CoPt}-\mathrm{TiO}_{2}$ recording layer in the medium. Wellisolated clusters with small grains were observed.

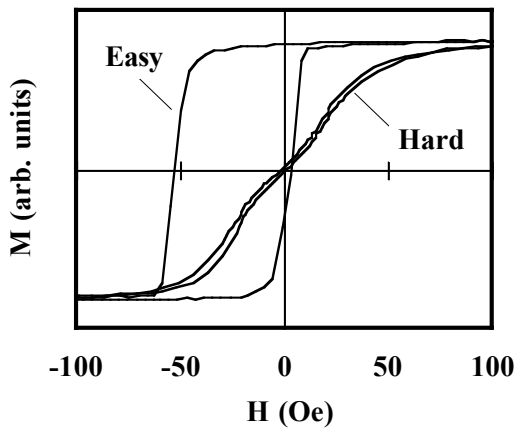

Fig. 4 M-H curve of the medium.

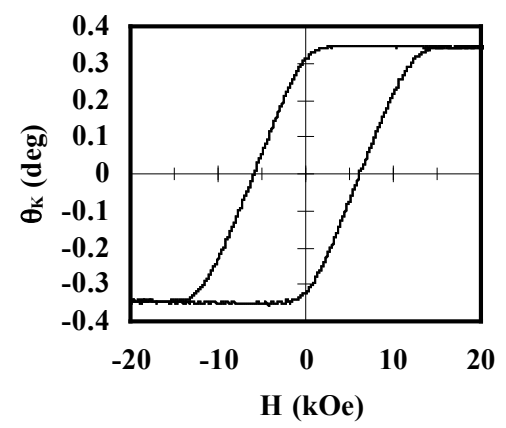

Fig. 5 Kerr loop of the medium.

From ref. 6, it seems that the small grains are composed of $\mathrm{CoPt}$, and that $\mathrm{TiO}_{2}$ is segregated in the grain boundaries. The small grains were $4-7 \mathrm{~nm}$ in diameter. The separation of the small grains was incomplete. A cluster included 5-15 of small grains. The clusters were generally oval. However, the uniformity of the shape was not good. The average area of the clusters was $213 \mathrm{~nm}^{2}$, which is much smaller than the maximum bit area of $1 \mathrm{Tbit}^{\mathrm{in}}{ }^{2}(645$ $\left.n m^{2}\right)$.

Figures 7(a) and 7(b) show cross-sectional TEM images of the medium. A clear columnar structure was observed. Large columns were formed from the $\mathrm{Pt}$ layer to the $\mathrm{CoPt}-\mathrm{TiO}_{2}$ layer, whose grain sizes in the lateral direction were constant as the film thickness was increased. Moreover, small columns with narrow grain boundaries were observed in the $\mathrm{CoPt}-\mathrm{TiO}_{2}$ recording layer. Wide grain boundaries between the large columns were also observed in this region.

On the basis of the TEM observations, a schematic illustration of the cross-section of the medium is shown in Fig. 8. The small grains of the $\mathrm{CoPt}$ film were separated due to the presence of $\mathrm{a} \mathrm{u}$ intermediate underlayer. On the other hand, wide boundaries surrounding the clusters with the small grains were formed at the positions of the columnar boundaries of the highly oriented SUL 


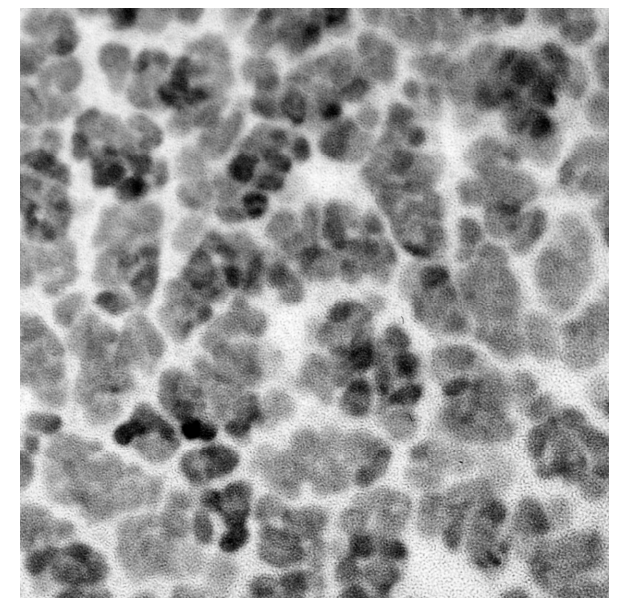

$10 \mathrm{~nm}$

Fig. 6 In-plane TEM image of the medium.

(a)

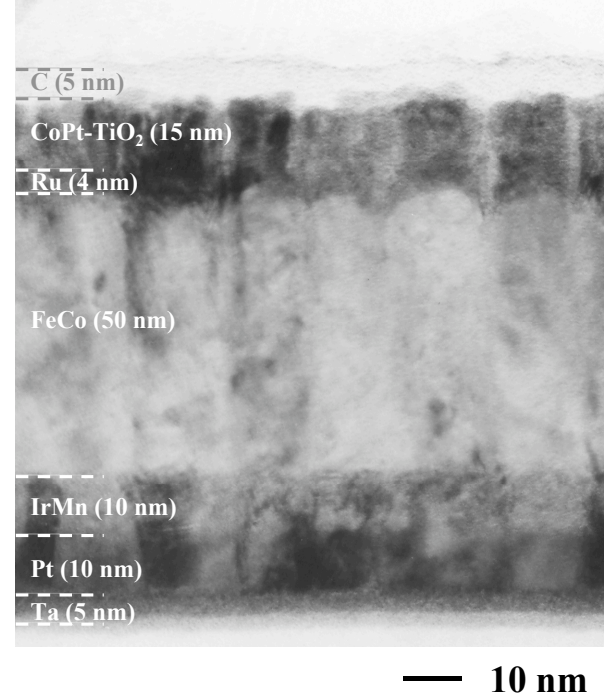

(b)
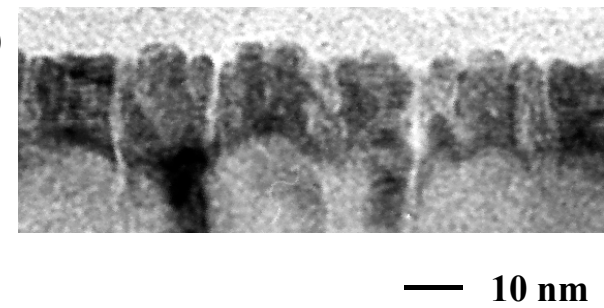

Fig. 7 Cross-sectional TEM images of the medium. (a) The whole film. (b) The CoPt-TiO $/ \mathrm{Ru} / \mathrm{FeCo}$ (thinner sample).

\section{Conclusions}

A granular-type medium with a highly oriented

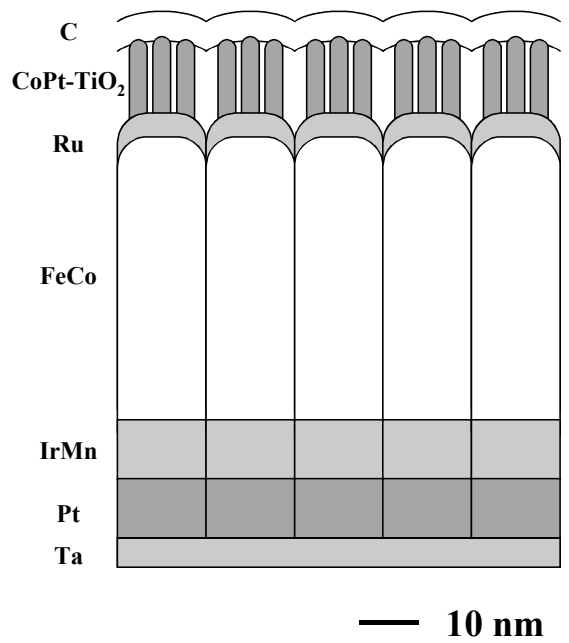

Fig. 8 Schematic illustration of the crosssection.

high- $B_{\mathrm{s}}$ FeCo SUL was prepared. Although the Ru intermediate layer thickness was only $4 \mathrm{~nm}$, the $\mathrm{CoPt}-\mathrm{TiO}_{2}$ recording layer had a high crystal orientation. The magnetic properties of the SUL and the recording layer were also good.

The CoPt- $\mathrm{TiO}_{2}$ recording layer in the medium has a novel granular structure, namely, well-isolated clusters composed of 5-15 small CoPt grains 4-7 nm in diameter segregated by $\mathrm{TiO}_{2}$. The clusters were generally oval, with an average area of $213 \mathrm{~nm}^{2}$.

At present, the shape and arrangement of the clusters cannot be controlled successfully. However, it seems that this new granular structure has the potential to enable high perpendicular recording densities.

Acknowledgements The author would like to thank Mr. J. Ariake for helpful discussions and Ms. S. Watanabe for TEM observations.

\section{References}

1) S. Iwasaki and K. Takemura, IEEE Trans. Magn., 11, 1173(1975).

2) K. Shintaku, K. Yamakawa, and K. Ouchi, J. Appl. Phys., 93, 6474(2003).

3) K. Shintaku and S. Watanabe, Trans. Magn. Soc. Jpn., 5, 22(2005).

4) K. Shintaku and S. Watanabe, J. Magn. Soc. Jpn., 30, 323(2006).

5) H. S. Jung and W. D. Doyle, IEEE Trans. Magn., 38, 2015(2002).

6) J. Ariake, T. Chiba, and N. Honda, IEEE Trans. Magn., 41, 3142(2005).

Received May. 08, 2006; Accepted Sep. 04, 2006 